\title{
COVID-19 Pandemic and Neonatal Health: What We Know
}

\author{
so Far? \\ Bhandari TR, ${ }^{1}$ Dangal G ${ }^{2}$
}

${ }^{1}$ Department of Public Health,

School of Health and Allied Sciences,

Pokhara University, Nepal.

${ }^{2}$ Kathmandu Model Hospital,

Bagbazzar, Kathmandu, Nepal.

\section{Corresponding Author}

Tulsi Ram Bhandari

Department of Public Health,

School of Health and Allied Sciences,

Pokhara University, Nepal.

E-mail: tulsib2004@gmail.com

\section{Citation}

Bhandari TR, Dangal G. COVID-19 Pandemic and Neonatal Health: What We Know so Far? Kathmandu Univ Med J. 2020;COVID-19 Special Issue 70(2):94-8.

\begin{abstract}
COVID-19 first time appeared in December 2019 in Wuhan, China. The number of cases increased rapidly in china and outside and the World Health Organization declared a pandemic on $11^{\text {th }}$ March 2020 . The pregnant and postpartum women, child, and neonatal populations are vulnerable to this disease due to immunological and physiological changes. This paper analyzed the published evidence for assessing the effect of COVID-19 on neonatal health and health care. Online published literature was searched from PubMed, Google Scholar, and other official webpages using keywords: "coronavirus/COVID-19/new coronavirus 2019"/SARS-CoV-2 and neonatal health/care/outcomes" and reviewed to prepare this article.

COVID-19 is the potential to transmit either mother to fetus or mother/caregiver to neonates. However, neonates born from infected mothers did not show significant clinical features. Pharyngeal-swab, amniotic-fluid, cord-blood, and breast-milk test results were not found positive. Health facility-based vaginal/caesarian delivery was considered a low risk of transmission. However, recommended to separate neonates with infected mothers/caregivers and test immediately after birth to avoid the possible transmission. Mothers/caregivers should take routine preventive measures such as washing hands frequently and avoiding contact with infected people. If neonates suffered from the server acute respiratory distress requires intensive care urgently. Despite the possibility of the intrauterine transmission of COVID-19 direct evidence is still lacking so it needs more studies for further confirmation. The International Pediatric Association suggested preventive programs, curative care, vaccination, and telemedicine care as the minimum services and called on its members to address these cares during the pandemic.
\end{abstract}

\section{KEY WORDS}

COVID-19, Neonatal care, Novel coronavirus, SARS-CoV-2, Vertical transmission

\section{INTRODUCTION}

Despite 19,854,544 infections, 730,523 deaths worldwide related to COVID-19 till August 09, 2020. The proportion of death and critically ill pregnant and postnatal women was reported as similar to other adults 1 and no evidence of vertical transmission. ${ }^{1-3}$ The mortality proportion of the COVID-19 in aged group 0-17 years neonates, children, and adolescents ranged from 0.04 to $0.06 \%$ respectively. ${ }^{4}$ However, there should be aware of the possible death among pregnant women with COVID-19 in the third trimester and their neonates. ${ }^{2}$

COVID-19 can increase stress to patients and healthcare providers and challenged the existing obstetric care. Obstetric care is time-sensitive and cannot be delayed. Hence, the prescribed procedures have to be offered considering the possible risks and safety. ${ }^{5}$ All neonates born from women with COVID-19 are susceptible to its infection but consistent evidence is still lacking. However, the clinical features were noticed milder and outcomes were also less severe/critical in neonates and children. ${ }^{6}$

COVID-19 was declared a Public Health Emergency of International Concern on 30 January 2020. ${ }^{7}$ The affected countries started lockdown and confined the mobility of the people to prevent and control the transmission. Most of the regular maternal, neonatal, and child health care programs were suspended for the time being. ${ }^{8}$

The International Pediatric Association recommended preventive and curative care as minimum healthcare 
services for neonates and children and called on its members to address these cares during the COVID-19 pandemic. ${ }^{8}$ This paper analyzed the online published evidence for assessing the effect of COVID-19 on neonatal health and health care.

For preparing this article, we searched and retrieved the published literature from PubMed and Google Scholar using various keywords: "coronavirus/COVID-19/new coronavirus 2019"/SARS-CoV-2 and neonatal health/care/ outcomes". We further searched the official webpages of the World Health Organization and other governmental and non-governmental organizations for the updated information.

\section{DISCUSSION}

\section{Epidemiology}

Coronavirus belongs to the subfamily of Coronaviridae which is an enclosed virus with a single strand, positivesense RNA genome. ${ }^{9}$ Before the emergence of SARS coronavirus (SARS-CoV) in 2003, there were two prototypes of human coronaviruses: HCoV-OC43 and HCoV-229E, both of which were the etiologic agents of the common cold which was low pathogenic to the human being. ${ }^{10-12}$ In 2003, SARS-CoV was identified that can cause severe acute respiratory syndrome (SARS) as it was the first example of serious illness in humans caused by a coronavirus. ${ }^{13-16}$ From that outbreak 8096 people affected in 30 countries and resulted in about 774 deaths and 9.6\% case-fatality rate. ${ }^{17,18}$ After 10 years of the outbreak of SARS-CoV in 2012 another highly pathogenic coronavirus was diagnosed in Saudi Arabia, it was named the Middle East Respiratory Syndrome Coronavirus (MERS-CoV) as it occurred only in Middle Eastern countries. ${ }^{19}$ There were 2494 confirmed cases and 856 associated deaths with a case-fatality rate of $34.4 \% .^{20}$

In December 2019, a local outbreak of pneumonia of unknown etiology was detected in Wuhan city of Hubei Province in China. ${ }^{21,22}$ These patients were epidemiologically linked to the seafood and wet animal wholesale market of Wuhan. ${ }^{23,24}$ The Chinese Center for Disease Control and Prevention (CCDC) immediately dispatched a rapid response team to conduct an epidemiologic and etiologic investigation in Wuhan, Hubei. The team collected three bronchoalveolar-lavage samples from Wuhan Jinyintan Hospital. It was observed that the virus genome was $85 \%$ identical with bat SARS-like CoV and it named 2019 novel coronavirus (2019-nCoV). ${ }^{25}$ On February 11, 2020, the International Committee on Taxonomy of Viruses (ICTV) declared that the name of 2019 novel coronavirus as SARSCoV-2.26,27 On $3^{\text {rd }}$ January 2020, the Government of the Chinese notified the WHO about the epidemic which was later confirmed to be 2019-nCoV and WHO announced the name of the disease caused by this novel virus as COVID-19. ${ }^{28}$ The number of cases increased rapidly in china and outside and WHO declared the COVID-19 outbreak as a pandemic on $11^{\text {th }}$ March $2020 .^{29}$

SARS-CoV-2 can transmit from person to person by respiratory droplets and close contact routes. The common modes of transmission are droplet infection, fomites, closed unprotected contact, arrosol-generating procedures in health care settings, and contaminated surfaces. Considering the recent publications World Health Organization suggested that there has been airborne transmission. However, the early findings need to be interpreted cautiously. ${ }^{30}$

\section{Clinical features}

The clinical features of the SARS-COV-2 virus in pregnant and postpartum women were found as similar as reported for adults and non-pregnant patients. The earliest common clinical features of the disease were fever $\left(\geq 100.4^{\circ} \mathrm{F}\right)$, runny nose, extreme sneezing, non-productive cough, sore throat, fatigue and exhaustion, breath shortness, diarrhea and/or vomiting, rapidly increased of heart bit, myalgia, chest pain, and headache. Some of the patients showed various complications including server sore throat, acute pneumonia, hemoptysis, and server diarrhea. ${ }^{31}$ Similarly, the pulmonary CT scan showed ground-glass opacity, patchy like shadows, fiber shadows, pleural effusion, and thickening shadow. ${ }^{3,32}$ But most of the pregnant women reported asymptomatic or mild stage, so laboratory technique qualitative real time polymerase chain reaction ( $q R T-P C R$ ) and radiological test (chest $C T$ ) were recommended to diagnose and prevent further transmission, and no indication for caesarian section. ${ }^{33}$ Out of the total COVID-19 infected women, $80 \%$ were found asymptomatic or mild, $15 \%$ percent had severity and five percent of women were in critical condition. ${ }^{34}$

The neonates born from COVID-19 infected mothers did not show significant clinical features as such asphyxia and invasive continuous airway pressure. Similarly, pharyngeal swab, amniotic fluid, breast milk and the cord-blood test results were not found positive. The COVID-19 infection in late trimester pregnant women had no adverse outcomes in their neonates. However, a vaginal delivery is considered a low risk of intrapartum COVID-19 transmission to the new-born and recommended also to separate mothers and child immediately to avoid the possible risk of transmission after birth. ${ }^{35-37}$

Neonates and children are also at risk of the COVID-19 and they have distinctive clinical features compared with adults and elders. However, children with COVID-19 had low incidence, slight clinical characteristics, a short course of the disease, and few severe cases of the disease. Hence, they need specific laboratory and radiological tests for the timely diagnosis. ${ }^{38}$

\section{Diagnosis of COVID-19}

For effective prevention and control of the COVID-19 timely 
testing and confirmatory testing is required condition. However, diagnosis of the disease is primarily based on epidemiological history, the manifestation of clinical signs and symptoms and laboratory and radiological examinations such as nucleic acid detection by real-time quantitative polymerase chain reaction (RT-qPCR) and high-throughput sequencing of the whole genome tests, CT scan of lungs, and antibody identification techniques (point-of-care testing -POCT) of IgM/IgG, ELISA test and blood culture. Currently, various rapid diagnostic test kits are available which were found to be clinically effective for conducting population-based screening and management of the COVID-19 disease. RT-qPCR is a specific test for confirming the COVID-19. However, considering the false reporting rate of the RT-qPCR laboratory scientists suggest both TR-qPCR and CT scan for the precise diagnosis of the COVID-19. ${ }^{39-45}$

\section{Management of neonates born to COVID-19 women}

COVID-19 is not an indication of cesarean section. However, RT-qPCR test and/or CT scan screening on admission may reduce the risk of nosocomial transmission SARSCOV-2 during the pandemic. ${ }^{33}$ None of the neonates born with COVID-19 women found vertical transmission and developed clinical, radiologic, hematologic and biochemical evidence of the COVID-19. However, natal care has to be provided with caution and neonates should be separated immediately from the infected mothers and caregivers. ${ }^{46}$ SARS-COV-2 is not transmitted through mother's milk so Donor Milk Banking is predicted always on the protection, promotion and support of breast milk to the neonates. Lockdown, quarantine and isolation were to be found effective control measures of the COVID-19 which may decrease the breastfeeding rates, supply and use of donor milk during this very unstable and concerning of times. ${ }^{47}$

Most of the studies showed no evidence of the vertical transmission of the COVID-19 cases. Even though protective measures and confirmatory tests are recommended on the admission of pregnant women with COVID-19 to prevent unexpected outcomes and cross-infection throughout intra-natal and perinatal times. ${ }^{48}$ for providing the essential neonatal health care and addressing neonatal health issues during COVID-19 pandemic the state must be as prepared, adaptable, efficient as possible to make the most of the available human and physical resources. ${ }^{49}$

During the pandemic of COVID-19, shortage of blood and its products are global concerns. For reducing the maternal and neonatal deaths the management of blood for obstetric care is a cost effective strategy that should be applied with urgency. ${ }^{50}$ The parents of the neonates infected by COVID-19 may suffer emotional and psychological stress, thus health care providers should counsel them frequently about the current condition and urgent needs of the neonates. ${ }^{51}$

The information presented in this article were based on the online published literature from $1^{\text {st }}$ December to $9^{\text {th }}$ August 2020.

\section{CONCLUSION}

The findings of the previous studies suggest no evidence of vertical transmission. Neonates and children are at risk of the COVID-19 due to immunological and physiological changes and they have distinctive clinical features compared with adults and elders. However, the clinical features were noticed milder and outcomes were also less severe/critical in neonates and children compared to adults. Despite the possibility of the intrauterine infection of COVID-19 direct evidence is still lacking so it needs more comprehensive studies for further validation of the vertical transmission. Health care providers are suggested to continue preventive programs, curative care, vaccination, and telemedicine care as the minimum health care services for neonates and called on to address these cares during the COVID-19 pandemic.

\section{ACKNOWLEDGMENT}

We would like to thank the authors and publishers of the reviewed literature whose effort made this article possible.

5. Deprest J, Choolani M, Chervenak F, Farmer D, Lagrou K, Lopriore E, et al. Fetal Diagnosis and Therapy during the COVID-19 Pandemic: Guidance on Behalf of the International Fetal Medicine and Surgery Society. Fetal Diagn Ther. 2020;1-10.

6. Zhang Z-J, Yu X-J, Fu T, Liu Y, Jiang Y, Yang BX, et al. Novel coronavirus infection in newborn babies under 28 days in China. Eur Respir J. 2020;

7. Coronavirus Disease (COVID-19) - events as they happen [Internet] [cited 2020 Jun 1]. Available from: https://www.who.int/emergencies/ diseases/novel-coronavirus-2019/events-as-they-happen

8. Klein JD, Koletzko B, El-Shabrawi MH, Hadjipanayis A, Thacker $\mathrm{N}$, Bhutta Z. Promoting and supporting children's health and healthcare during COVID-19 International Paediatric Association Position Statement. Arch Dis Child. 2020; 
9. Weiss SR, Navas-Martin S. Coronavirus pathogenesis and the emerging pathogen severe acute respiratory syndrome coronavirus. Microbiol Mol Biol Rev. 2005;69:635-64.

10. Mclntosh K. Coronaviruses: a comparative review. In: Current Topics in Microbiology and Immunology/Ergebnisse der Mikrobiologie und Immunitätsforschung. Springer; 1974. p. 85-129.

11. Hamre D, Procknow JJ. A new virus isolated from the human respiratory tract. Proc Soc Exp Biol Med. 1966;121:190-3.

12. Su S, Wong G, Shi W, Liu J, Lai AC, Zhou J, et al. Epidemiology, genetic recombination, and pathogenesis of coronaviruses. Trends Microbiol. 2016;24:490-502.

13. Rota PA, Oberste MS, Monroe SS, Nix WA, Campagnoli R, Icenogle JP, et al. Characterization of a novel coronavirus associated with severe acute respiratory syndrome. Science. 2003;300:1394-9.

14. Zhong NS, Zheng BJ, Li YM, Poon LLM, Xie ZH, Chan KH, et al. Epidemiology and cause of severe acute respiratory syndrome (SARS) in Guangdong, People's Republic of China, in February, 2003. The Lancet. 2003;362:1353-8.

15. Drosten C, Günther S, Preiser W, Van Der Werf S, Brodt H-R, Becker $S$, et al. Identification of a novel coronavirus in patients with severe acute respiratory syndrome. N Engl J Med. 2003;348:1967-76.

16. Ksiazek TG, Erdman D, Goldsmith CS, Zaki SR, Peret T, Emery S, et al. A novel coronavirus associated with severe acute respiratory syndrome. N Engl J Med. 2003;348:1953-66.

17. Peiris JSM, Guan Y, Yuen KY. Severe acute respiratory syndrome. Nat Med. 2004;10:S88-S97.

18. WHO | Summary of probable SARS cases with onset of illness from 1 November 2002 to 31 July 2003 [Internet]. WHO. World Health Organization; [cited 2020 Jun 9]. Available from: https://www.who. int/csr/sars/country/table2004_04_21/en/

19. Zaki AM, Van Boheemen S, Bestebroer TM, Osterhaus AD, Fouchier RA. Isolation of a novel coronavirus from a man with pneumonia in Saudi Arabia. N Engl J Med. 2012;367:1814-20.

20. WHO | Middle East respiratory syndrome coronavirus (MERS-CoV) [Internet]. [cited 2020 Jun 9]. Available from: https://www.who.int/ emergencies/mers-cov/en/

21. Commission WMH. Report of clustering pneumonia of unknown etiology in Wuhan City. Wuhan Munic Health Comm Wuhan City Health Comm. 2019;

22. WHO | Pneumonia of unknown cause - China [Internet]. WHO. World Health Organization; [cited 2020 Jun 9]. Available from: http://www. who.int/csr/don/05-january-2020-pneumonia-of-unkown-causechina/en/

23. Lu H, Stratton CW, Tang Y-W. Outbreak of Pneumonia of Unknown Etiology in Wuhan China: the Mystery and the Miracle. J Med Virol.

24. Bogoch II, Watts A, Thomas-Bachli A, Huber C, Kraemer MU, Khan K. Pneumonia of Unknown Etiology in Wuhan, China: Potential for International Spread Via Commercial Air Travel. J Travel Med. 2020;

25. Zhu N, Zhang D, Wang W, Li X, Yang B, Song J, et al. A novel coronavirus from patients with pneumonia in China, 2019. N Engl J Med. 2020;

26. Naming the coronavirus disease (COVID-19) and the virus that causes it [Internet]. [cited 2020 Jun 9]. Available from: https://www.who.int/ emergencies/diseases/novel-coronavirus-2019/technical-guidance/ naming-the-coronavirus-disease-(covid-2019)-and-the-virus-thatcauses-it

27. of the International CSG. The species Severe acute respiratory syndrome-related coronavirus: classifying 2019-nCoV and naming it SARS-CoV-2. Nat Microbiol. 2020;5:536.

28. WHO Statement Regarding Cluster of Pneumonia Cases in Wuhan, China [Internet]. [cited 2020 Jun 9]. Available from: https://www. who.int/china/news/detail/09-01-2020-who-statement-regardingcluster-of-pneumonia-cases-in-wuhan-china
29. WHO announces COVID-19 outbreak a pandemic [Internet]. World Health Organization; 2020 [cited 2020 Jun 9]. Available from: http://www.euro.who.int/en/health-topics/health-emergencies/ coronavirus-covid-19/news/news/2020/3/who-announces-covid-19outbreak-a-pandemic

30. Modes of transmission of virus causing COVID-19: implications for IPC precaution recommendations [Internet]. [cited $2020 \mathrm{Jul}$ 9]. Available from: https://www.who.int/news-room/commentaries/detail/ modes-of-transmission-of-virus-causing-covid-19-implications-foripc-precaution-recommendations

31. Abd El-Aziz TM, Stockand JD. Recent progress and challenges in drug development against COVID-19 coronavirus (SARS-CoV-2)-an update on the status. Infect Genet Evol. 2020;104327.

32. Clinical features and outcomes of pregnant women suspected of coronavirus disease 2019 - ScienceDirect [Internet]. [cited 2020 May 31]. Available from: https://www.sciencedirect.com/science/article/ pii/S0163445320302127?casa_token=tEvhGb28y5kAAAAA:oufqban MYlgp7ZN2CAaS4EDesBNASXW1bUKde0DWs2mei6rT1KFMTc4j7Pm KyWDwPOdLe-78Wjb9

33. Cao D, Yin H, Chen J, Tang F, Peng M, Li R, et al. Clinical analysis of ten pregnant women with COVID-19 in Wuhan, China: A retrospective study. Int J Infect Dis. 2020;

34. Breslin N, Baptiste C, Gyamfi-Bannerman C, Miller R, Martinez $\mathrm{R}$, Bernstein $\mathrm{K}$, et al. COVID-19 infection among asymptomatic and symptomatic pregnant women: Two weeks of confirmed presentations to an affiliated pair of New York City hospitals. Am J Obstet Gynecol MFM. 2020;100118.

35. Ferrazzi E, Frigerio L, Savasi V, Vergani P, Prefumo F, Barresi S, et al. Vaginal delivery in SARS-CoV-2 infected pregnant women in Northern Italy: a retrospective analysis. BJOG Int J Obstet Gynaecol. 2020;

36. Yang $P$, Wang $X$, Liu $P$, Wei $C$, He B, Zheng J, et al. Clinical characteristics and risk assessment of newborns born to mothers with COVID-19. J Clin Virol. 2020;104356.

37. Yu N, Li W, Kang Q, Xiong Z, Wang S, Lin X, et al. Clinical features and obstetric and neonatal outcomes of pregnant patients with COVID-19 in Wuhan, China: a retrospective, single-centre, descriptive study. Lancet Infect Dis. 2020;

38. Duan Y, Zhu Y, Tang L, Qin J. CT features of novel coronavirus pneumonia (COVID-19) in children. Eur Radiol. 2020;1-7.

39. Li Y, Xia L. Coronavirus disease 2019 (COVID-19): role of chest CT in diagnosis and management. Am J Roentgenol. 2020;214:1280-6.

40. Iyer M, Jayaramayya K, Subramaniam MD, Lee SB, Dayem AA, Cho S-G, et al. COVID-19: an update on diagnostic and therapeutic approaches. BMB Rep. 2020;53:191.

41. Rashid ZZ, Othman SN, Samat MNA, Ali UK, Wong KK. Diagnostic performance of COVID-19 serology assays. Malays J Pathol. 2020:42:13-21.

42. Chan JF-W, Yip CC-Y, To KK-W, Tang TH-C, Wong SC-Y, Leung K-H, et al. Improved molecular diagnosis of COVID-19 by the novel, highly sensitive and specific COVID-19-RdRp/Hel real-time reverse transcription-PCR assay validated in vitro and with clinical specimens. J Clin Microbiol. 2020;58.

43. Tang $Y-W$, Schmitz JE, Persing DH, Stratton CW. Laboratory diagnosis of COVID-19: current issues and challenges. J Clin Microbiol. 2020;58.

44. Li X, Geng M, Peng Y, Meng L, Lu S. Molecular immune pathogenesis and diagnosis of COVID-19. J Pharm Anal. 2020;

45. Organization WH. Population-based age-stratified seroepidemiological investigation protocol for coronavirus 2019 (COVID-19) infection, 26 May 2020. World Health Organization; 2020.

46. Liu W, Wang J, Li W, Zhou Z, Liu S, Rong Z. Clinical characteristics of 19 neonates born to mothers with COVID-19. Front Med. 2020;1-6. 
47. Marinelli KA. International perspectives concerning donor milk banking during the SARS-CoV-2 (COVID-19) pandemic. J Hum Lact. 2020;0890334420917661.

48. Chen S, Liao E, Cao D, Gao Y, Sun G, Shao Y. Clinical analysis of pregnant women with 2019 novel coronavirus pneumonia. J Med Virol. 2020;

49. Saggers RT, Ramdin TD, Bandini RM, Ballot DE. COVID-19 preparedness in a neonatal unit at a tertiary hospital in Johannesburg, South Africa. Wits J Clin Med. 2020;2:43.
50. Barrett CL. Obstetric anaemia in Africa in the time of COVID-19: a call to action. ISBT Sci Ser.

51. Fan J, Zhou M, Wei L, Fu L, Zhang X, Shi Y. A Qualitative Study on the Psychological Needs of Hospitalized Newborns' Parents During COVID-19 Outbreak in China. Iran J Pediatr. 2020;30. 